\title{
ON THE CONCEPT OF TIME IN EVERYDAY LIFE AND BETWEEN PHYSICS AND MATHEMATICS
}

\author{
PAOLO DI SIA ${ }^{1-4}$ \\ ${ }^{1}$ University of Padova, School of Science, Department of Physics and Astronomy \& \\ Department of Chemical Science, Padova, Italy \\ ${ }^{2}$ University of Padova, School of Medicine, Department of Neurosciences, Padova, Italy \\ ${ }^{3}$ paolo.disia@gmail.com \\ ${ }^{4}$ www.paolodisia.com
}

\begin{abstract}
In this paper I consider the concept of time in a general way as daily human time and then within physics with relation to mathematics. I consider the arrow of time and then focus the attention on quantum mechanics, with its particular peculiarities, examining important concepts like temporal asymmetry, complexity, decoherence, irreversibility, information theory, chaos theory. In conclusion I consider the notion of time connected to a new theory in progress, called "Primordial Dynamic Space" theory.
\end{abstract}

Keywords: Time, Modern Physics, Irreversibility, Decoherence, Symmetry/Asymmetry, Entanglement, Complexity, Primordial Dynamic Space (PDS) Theory, Education.

\section{Introduction}

\section{Time and irreversibility}

Superposition and entanglement

Quantum mechanics between innovation and complexity

Information, complexity and arrow of time

"Past hypothesis", gravity and arrow of time

\section{Recent advances on the concept of time}




\section{Conclusion}

\section{References}

Ali, T., Bhattacharyya, A., Shajidul Haque, S., Kim, E.H., Moynihan, N., and Murugan, J. (2020).

Becker, A. (2019).

Belavkin, V.P., and Ohya, M. (2002).

Butterfield, J., Pagonis, C. (2010).

Canales, J. (2016).

Chaichian, M., Oksanen, M., Tureanu, A. (2011).

Darrigol, O. (2018).

Di Sia, P. (2015 a). Looking at the Dimension of Time among Science, Psychology and

Everyday Reality, International Letters of Social and Humanistic Sciences (ILSHS), 1(2), 146-153.

Di Sia, P. $\left(2015^{\mathrm{b}}\right)$. Approaching youngs to unified theories: the charm of string theories, Procedia - Social and Behavioral Sciences Journal, 174C, 10-16.

Di Sia, P. (2017). A Hystorical-Didactic Introduction To The Key Concepts Of Mathematical Analysis, TOJET (The Online Journal of Educational Technology), 60-68.

Di Sia, P. (2018 ). Mindfulness, Consciousness and Quantum Physics, World Scientific News, 96, 25-34.

Di Sia, P. $\left(2018^{\text {b }}\right)$. On Quantum Physics, Metaphysics and Theism. In: Bertini, D., Migliorini, D. (Eds), Relations. Ontology and Philosophy of Religion, Milan-London: Mimesis International.

https://www.amazon.com/Relations-Ontology-Philosophy-Daniele-Bertini/dp/8869771261.

Di Sia, P. (2020). On philosophy of mind, quantum physics and metaphysics of the uni-multiverse, Philosophical News - Official publication of the European Society for Moral Philosophy, 18, 161-174. https://www.philosophicalnews.com/issues/issue-n-18/.

Di Sia, P. $\left(2020^{b}\right)$. About Some Difficulties of Cosmology and New Ideas for Solving Them. Ergonomics International Journal (EOIJ), 4(2), 000231 (5 pp).

https://medwinpublishers.com/EOIJ/EOIJ16000231.pdf.

Di Sia, P., Bhadra, N.K. (2020 $)$. Origin of consciousness and contemporary physics, World Scientific News, 140, 127-138.

Di Sia, P., Bhadra, N.K. $\left(2020^{\mathrm{b}}\right)$. Everything in a part: about the creation of universe and consciousness, Ergonomics International Journal (EOIJ), 4(1), 000228 (6 pp).

Di Sia, P. $\left(2021^{\text {a }}\right)$. A new unified theory based on the "Primordial Dynamic Space" structure" Preprint doi: 10.31219/osf.io/26s35, https://osf.io/26s35/.

Di Sia, P. $\left(2021^{\text {b }}\right)$. On the Concept of Time between Physics and Neuroscience (submitted).

Di Sia, P. $\left(2021^{c}\right)$. On advances of contemporary physics about mind and consciousness (submitted). 
Fraisse, P. (1963).

Gallagher, R., Appenzeller, T., Normile, D., Service, R.F. et al. (1999).

Griffiths, D.J., Schroeter, D.F. (2018).

Jost, J.D., Home, J.P., Amini, J.M., Hanneke, D., Ozeri, R., Langer, C., Bollinger, J.J., Leibfried, D., Wineland, D.J. (2009).

Kiefer, C., Joos, E. (1998).

Kondepudi, D., Petrosky, T., and Pojman, J.A. (2017).

Mari, A., De Palma, G. \& Giovannetti, V. (2016).

McGucken, E. (2017).

Mersini-Houghton, L., Vaas, R. (Eds) (2012).

Nielsen, M.A., Chuang, I.L. (2000).

Price, H. (2013).

Prigogine, I. (1997).

Prigogine, I., Stengers, I. (1984).

Rueger, A., McGivern, P. (2010).

Saint Augustine. (1961).

Savitt, S.F. (Ed.) (1997).

Schroeder, D.V. (1999).

Zeh, H.D. (2002).

Zurek, W.H. (2003). 